\title{
PREVENTION OF COVID-19 IN OLDER ADULTS: A BRIEF GUIDANCE FROM THE INTERNATIONAL ASSOCIATION FOR GERONTOLOGY AND GERIATRICS (IAGG) ASIA/OCEANIA REGION
}

\author{
J.K. CHHETRI ${ }^{1,2}$, P. CHAN ${ }^{1}$, H. ARAI ${ }^{3}$, S. CHUL PARK ${ }^{4}$, P. SRIYANI GUNARATNE ${ }^{5}$, S. SETIATI ${ }^{6}$, \\ P. ASSANTACHAI ${ }^{7}$ ON BEHALF OF THE INTERNATIONAL ASSOCIATION FOR GERONTOLOGY \\ AND GERIATRICS-ASIA/OCEANIA REGION
}

1. National Clinical Research Center for Geriatric Disorders, Xuanwu Hospital of Capital Medical University, Beijing, China; 2. Nepalese Society of Gerontology and Geriatrics; 3. National Center for Geriatrics and Gerontology, Japan; 4. The Future Life and Society Research Center, Chonnam National University, Gwangju, Republic of Korea; 5. Sri Lankan

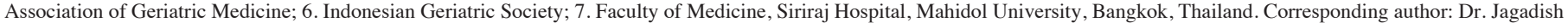
K Chhetri M.D, Xuanwu Hospital of Capital Medical University, No. 45 Changchun Street, Xicheng District, Beijing 100053, China, E-mail:chhetri_jk@hotmail.com, Tel: +86-10-83198677

Key words: COVID-19, coronavirus, older adults, elderly.

The world is currently facing a pandemic of a new coronavirus commonly known as COVID-19. According to the World Health Organization (WHO) over one million people worldwide are now infected with COVID-19 and over 50,000 deaths have been confirmed so far (updated April 4, 2020) (1). It is now evident that older people are amongst the most vulnerable population with a mortality rate of approximately 15\% (2-4). In addition, people with pre-existing chronic conditions such as diabetes, cardiovascular disease, lung disease, hypertension, and cancer are at increased risk of mortality $(2,3,5,6)$. Although, the spread of the virus in China, the Republic of Korea and Singapore is mostly under control, other countries like Italy and the United States are facing the tsunami of COVID-19 with a high case fatality rate. Very few regions are now free from this pandemic and the Asia-Oceania region is no exception. In the Asia-Oceania region countries like Iran, Australia, Malaysia, Philippines, Japan, India now have the highest number of new cases (Table 1). More and more countries in the region are reporting the escalating number of new cases, which might soon overflow if appropriate countermeasures are not provided. The Asia-Oceania region constitutes countries with a large population (such as China, India, and Indonesia) and thus with a higher proportion of older adults (7), which is already a challenge (i.e., enable them to maintain autonomy in old age) for geriatrics medicine even in the absence of an outbreak. Now, at the verge of this pandemic there is an additional challenge to save these older population (8). Besides, this region consists of many low and middle income countries. While many high income countries are still struggling to fight the pandemic, the Asia-Oceania region with many poor and developing countries (with fewer resources) should be prepared to face the escalating outbreak.

We as the members of the International Association for Gerontology and Geriatrics, Asia/Oceania (IAGG-AO) region feel the need for disseminating some recommendations for protecting the older population in this region. In the absence of appropriate treatment or vaccine till date, each country has developed its unique characteristics to fight the current threat Received April 6, 2020 based on the availability of resources. Under such conditions we believe that prevention is the best way to protect the most vulnerable older population. At this state of crisis, while all of the healthcare workers and policymakers are doing their best to flatten the curve of COVID-19, it might be impossible to draft a consensus guideline regarding the prevention of COVID19 infection in the older adults of the Asia-Oceania region. However, a direct message that is easy to disseminate, easy to understand may be useful to prevent the spread of COVID-19 infection in the region. Based on various preventive strategies being implemented in the region, we propose the mnemonic COVID-IAGG-AO (Table 2.) as a basic guidance to prevent COVID-19 in older adults.

\section{Table 1}

Top ten COVID-19 affected countries in the Asia-Oceania region (updated April 4, 2020) (1)

\begin{tabular}{lcccc}
\hline Country & $\begin{array}{c}\text { Total } \\
\text { confirmed } \\
\text { cases }\end{array}$ & $\begin{array}{c}\text { Total } \\
\text { confirmed } \\
\text { new cases }\end{array}$ & $\begin{array}{c}\text { Total } \\
\text { confirmed } \\
\text { deaths }\end{array}$ & $\begin{array}{c}\text { Total } \\
\text { confirmed } \\
\text { new deaths }\end{array}$ \\
\hline China & 82875 & 73 & 3335 & 4 \\
Iran & 53183 & 2715 & 3294 & 134 \\
Republic of Korea & 10156 & 94 & 177 & 3 \\
Australia & 5454 & 230 & 28 & 5 \\
Malaysia & 3333 & 217 & 53 & 3 \\
Philippines & 3018 & 385 & 136 & 29 \\
Japan & 2920 & 303 & 69 & 4 \\
Indonesia & 2491 & 218 & 209 & 11 \\
Pakistan & 2450 & 0 & 35 & 0 \\
India & 2301 & 336 & 56 & 6 \\
Saudi Arabia & 2039 & 154 & 25 & 4 \\
\hline
\end{tabular}




\section{PREVENTION OF COVID-19 IN OLDER ADULTS}

Table 2

The COVID-IAGG-AO guidance

\begin{tabular}{ll}
\hline C & Catnap (get adequate sleep) \\
O & Optimistic (emotion to prevent depression) \\
V & Vigor (active exercise indoor) \\
I & Intake (adequate nutrition and maintain oral hygiene) \\
D & Distancing \\
I & $\begin{array}{l}\text { Increase your social support/social contact through communication technology } \\
\text { with family/friends }\end{array}$ \\
A & Administer routine medicine \\
G & Get enough sunlight in the morning \\
G & $\begin{array}{l}\text { Go to Emergency Room/ Call emergency services if shortness of breath, chest } \\
\text { pain, continuous fever, decrease food intake, feeling fatigued all the time, or }\end{array}$ \\
& when your caregiver/family cannot wake you up or you cannot communicate \\
A & $\begin{array}{l}\text { Actively washing your hand with sanitizer or soap } \\
\text { O }\end{array} \quad$ Order your food and medical supplies through your family/caregiver/online \\
\hline
\end{tabular}

Rationale for the COVID-IAGG-AO guidance: Older people are known to have poor immune system thus largely susceptible to the infection. Proper sleep, getting proper food and exercise may help to maintain the immunity in old age and prevent frailty (i.e., a geriatric syndrome with added vulnerability to stressors (9)). One of the most convenient ways to prevent COVID-19 infection is physical distancing from others, but it may lead to loneliness and increase the risk of depression. Being optimistic or being mentally resilient one can avoid such mental problems during a crisis. Another way of keeping a healthy mental status is by keeping constant social interaction through means of communication such as the internet and other media tools. Getting enough sunlight in the morning may provide Vitamin D which may reduce the risk of infection in older adults with suboptimal levels of Vitamin D (10). Many older people are known to have some comorbidities and should be careful in taking their routine medication even in isolation. They should ask the help of family members/caregivers to get their daily needs including medical supplies. Online shopping may be used if available. In the case of respiratory symptoms such as shortness of breath, chest pain, continuous fever or cough, fatigue and having decreased awareness emergency services should be called or one should visit the hospital emergency room. Last but not least is to disinfect one's hand when possible using sanitizer or soap so as to stop the spread of the virus.

In conclusion, we advise all healthcare workers, family members and caregivers of older people in the Asia-Oceania region to actively implement COVID-IAGG-AO as a basic guidance to prevent the infection of COVID-19 in the older population. We sincerely hope that the crisis of the pandemic will end soon. Furthermore, we need to be even more well prepared for the post-COVID negative effect management of the older adults in the region and worldwide, which is another challenging task.

Conflict of interest: None

\section{References}

1. Novel Coronavirus (2019-nCoV) situation reports Available at: https://www.who.int/ emergencies/diseases/novel-coronavirus-2019/situation-reports. Accessed April 5, 2020 .

2. Wu Z, McGoogan JM. Characteristics of and Important Lessons From the Coronavirus Disease 2019 (COVID-19) Outbreak in China: Summary of a Report of 72314 Cases From the Chinese Center for Disease Control and Prevention. JAMA. 2020; doi:10.1001/jama.2020.2648.

3. Morley JE, Vellas B. COVID-19 and Older Adult. J Nutr Health Aging. 2020;24(4):364-365

4. Added vulnerability of frail older Population to COVID-19. Available at: https://www bmj.com/content/368/bmj.m1091/rr-1. Accessed April 6, 2020.

5. Coronavirus Age, Sex, Demographics (COVID-19) - Worldometer Available at: https://www.worldometers.info/coronavirus/coronavirus-age-sex-demographics/. Accessed April 5, 2020

6. Cesari M, Proietti M. Geriatric Medicine in Italy in the Time of Covid-19. J Nutr Health Aging, 2020. doi:10.1007/s12603-020-1354-z.

7. Chhetri JK, Chan P, Ma L, Peng D, Rodríguez-Mañas L, Cesari M, Vellas B. Prevention of Disability in the Frail Chinese Older Population. J Frailty Aging 2019;8:2-6.

8. Landi F, Barillaro C, Bellieni A, et al. The New Challenge of Geriatrics: Saving Frail Older People from the SARS-CoV-2 Pandemic Infection. J Nutr Health Aging. 2020;doi:10.1007/s12603-020-1356-x.

9. Fried LP, Tangen CM, Walston J, Newman AB, Hirsch C, Gottdiener J, Seeman T, Tracy R, Kop WJ, Burke G, McBurnie MA, Cardiovascular Health Study Collaborative Research Group. Frailty in older adults: evidence for a phenotype. J Gerontol A Biol Sci Med Sci 2001;56:M146-156.

10. Grant WB, Lahore H, McDonnell SL, Baggerly CA, French CB, Aliano JL, Bhattoa HP. Evidence that Vitamin D Supplementation Could Reduce Risk of Influenza and COVID-19 Infections and Deaths. Nutrients 2020;12:988. 